\title{
Treatment of recurrent respiratory papillomatosis and adverse reactions following off-label use of cidofovir (Vistide ${ }^{\circledR}$ )
}

\author{
Robin E. A. Tjon Pian Gi • Andreas Dietz • Vojko Djukic • Hans E. Eckel • \\ Gerhard Friedrich • Wojciech Golusinski • Anastasios Hantzakos • \\ George Lawson • Marc Remacle · Heikki Rihkanen · Frederik G. Dikkers
}

Received: 27 July 2011/ Accepted: 6 October 2011/Published online: 22 October 2011

(C) The Author(s) 2011. This article is published with open access at Springerlink.com

Recurrent respiratory papillomatosis (RRP) is caused by a human papilloma virus (HPV). It is a rare, sometimes debilitating disease compromising voice and airway. RRP is characterized by a variable course of disease, potentially leading to frequent annual surgical procedures, the number of which may exceed a hundred during the life time. The therapy focuses on surgical removal of the mucosal lesions in order to keep the airway open and the voice satisfactory. Till now, there is no curative therapy for the virus infection in itself. As recurrent surgery alone has proven to be insufficient in many cases, adjuvant therapy is increasingly being used. One of the mainstays of adjuvant therapy is the administration of intralesional cidofovir $\left(\right.$ Vistide $\left.^{\circledR}\right)$.

Cidofovir is an antiviral agent, registered for the treatment of cytomegalovirus (CMV) retinitis in patients with AIDS. Since 1998 the drug has been used to treat patients

R. E. A. Tjon Pian Gi · F. G. Dikkers ( $₫)$

Department of Otorhinolaryngology, University of Groningen,

University Medical Center Groningen, P.O. Box 30.001,

9700RB Groningen, Netherlands

e-mail: f.g.dikkers@umcg.nl

\section{A. Dietz}

Department of Otorhinolaryngology,

University of Leipzig, Leipzig, Germany

\section{Djukic}

Department of Otorhinolaryngology, Medical Center,

University of Belgrade, Belgrade, Yugoslavia

\section{H. E. Eckel}

Department of Otorhinolaryngology, Klinikum Klagenfurt,

Klagenfurt am Wörthersee, Austria

G. Friedrich

Department of Otorhinolaryngology,

Medical University of Graz, Graz, Austria with RRP [1]. Cidofovir can be regarded as a prodrug. It exerts the antiviral effect by decreasing the efficiency of DNA transcription following incorporation into the growing DNA chain [2]. Its use has been advocated in cases of papilloma refractive to repeated surgery, either due to its spread, or to its recurrence rate. Some case reports and series showed the effect of cidofovir treatment with few or no side effects [3-8]. The only prospective double-blind randomized controlled trail showed a significant improvement in the Derkay severity score between the cidofovir and placebo group but failed to show significant benefit in number of procedures performed [9].

On January 31 2011, an alarming news was communicated by Gilead (the producer of cidofovir) concerning very serious side effects of its off-label use [10]. The warning included reports on nephrotoxicity, neutropenia,

W. Golusinski

Department of Otorhinolaryngology,

Greater Poland Cancer Centre, Poznan, Poland

A. Hantzakos

Department of Otorhinolaryngology,

Hippocrateion General Hospital,

University of Athens, Athens, Greece

G. Lawson · M. Remacle

Department of Otorhinolaryngology,

University Hospital of Louvain de Mont-Godinne,

Yvoir, Belgium

H. Rihkanen

Department of Otorhinolaryngology,

Helsinki University Hospital, Espoo, Finland 
oncogenicity and even some fatalities. The manufacturer emphasized that cidofovir is formulated for intravenous infusion only and the indication is CMV infection of AIDS patients. The manufacturer did not specify the severity of the reported complications, neither the off-label indication of the drug nor its way of administration. Unfortunately, up to the end of May 2011 the above mentioned communication was not received by the laryngologists in most countries.

The warning caused a lot of discussion within the European Laryngological Society (ELS). The ELS (having $>350$ active members) is the main laryngological organization in Europe, representing laryngologists from more than 55 countries on all continents (http://www.elsoc.org). The ELS has taken its responsibility and initiated a research project on the side effects of off-label use of cidofovir in RRP patients.

The purpose of such a study is to determine whether there are known nephrotoxic, neutropenic, or oncogenic side effects after having used intralesional cidofovir in patients with RRP. Facts are needed to decide whether or not intralesional use of cidofovir in the larynx is safe or not. Side effects might be dose dependent, and occur as a consequence of the number of administrations, the interval between applications or the cumulative dose. To determine the aforementioned, a multicenter retrospective analysis has been initiated among members of the ELS for which, among others, all members of its Scientific Council have been approached.

Parallel to the retrospective study we are conducting an update on reported side effects in the literature.

Reports of the studies will be submitted for publication in the official journal of the ELS, the European Archives of Otorhinolaryngology, Head and Neck Surgery.

Conflict of interest None
Open Access This article is distributed under the terms of the Creative Commons Attribution Noncommercial License which permits any noncommercial use, distribution, and reproduction in any medium, provided the original author(s) and source are credited.

\section{References}

1. Snoeck R, Andrei G, De Clercq E (1998) Specific therapies for human papilloma virus infections. Curr Opin Infect Dis 11:733-737

2. Cundy KC (1999) Clinical pharmacokinetics of the antiviral nucleotide analogues cidofovir and adefovir. Clin Pharmacokinet 36:127-143

3. Naiman AN, Ceruse P, Coulombeau B, Froehlich P (2003) Intralesional cidofovir and surgical excision for laryngeal papillomatosis. Laryngoscope 113:2174-2181

4. Pransky SM, Albright JT, Magit AE (2003) Long-term follow-up of pediatric recurrent respiratory papillomatosis managed with intralesional cidofovir. Laryngoscope 113:1583-1587

5. Dikkers FG (2006) Treatment of recurrent respiratory papillomatosis with microsurgery in combination with intralesional cidofovir: a prospective study. Eur Arch Otorhinolaryngol 263:440-443

6. Bielamowicz S, Villagomez V, Stager SV, Wilson WR (2002) Intralesional cidofovir therapy for laryngeal papilloma in an adult cohort. Laryngoscope 112:696-699

7. Tanna N, Sidell D, Joshi AS, Bielamowicz SA (2008) Adult intralesional cidofovir therapy for laryngeal papilloma: a 10 year perspective. Arch Otolaryngol Head Neck Surg 134:497-500

8. Wierzbicka M, Jackowska J, Bartochowska A, Jozefiak A, Szyfter W, Kedzia W (2011) Effectiveness of cidofovir intralesional treatment in recurrent respiratory papillomatosis. Eur Arch Otorhinolaryngol 268:1305-1311

9. McMurray JS, Connor N, Ford CN (2008) Cidofovir efficacy in recurrent respiratory papillomatosis: a randomized, double-blind, placebo-controlled study. Ann Otol Rhinol Laryngol 117:477-483

10. Gillen D (2011) Direct healthcare professional communication regarding serious adverse reactions following off-label use of Vistide.http://www.cbg-meb.n1/NR/rdonlyres/FFB51936-EC22-4180A213-9E907F06A774/0/VistideDHPCletterJanuary2011.pdf. Accessed 12 January 2011 